\title{
La mayor experiencia del mundo. La narrativa de una maestra de infantil entre la actividad laboral, la enfermedad y la jubilación
}

\author{
The greatest experience in the world. A child's teacher's narrative \\ between work, illness and retirement
}

\author{
Víctor Amar ${ }^{1}$ \\ ${ }^{1}$ Universidad de Cádiz victor.amar@uca.es
}

Recibido: 2/12/2019

Aceptado: 8/2/2021

Copyright $(\mathrm{C}$

Facultad de CC. de la Educación y Deporte. Universidad de Vigo

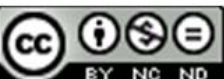

Dirección de contacto:

Víctor Amar

Facultad de Educación. Universidad de Cádiz

Campus Río San Pedro

11519 Puerto Real. Cádiz

\begin{abstract}
Resumen
Dicen que la maestra nace y se hace. En la mayoría de los casos, eso es posible. No obstante, y en este caso, está expuesta a un sinnúmero de circunstancias que pueden interferir en su desarrollo profesional e, incluso, personal. Pero la narrativa, como propuesta metodológica, nos sitúa en el lugar de una maestra de infantil que por motivos de salud es invitada a salir del sistema educativo, quedando jubilada. Por ello, el objetivo de la investigación es: "Conocer y comprender la trayectoria vital de una maestra de infantil una vez es jubilada por enfermedad". De modo que la entrevista nos aproxima a una profesional que sufre pero no sucumbe. No ha sido suficiente la enfermedad, sino que tendrá que enfrentar una nueva situación, igualmente no deseada. Una mujer que sabe que está cualificada y que podría seguir vinculada a su trabajo. Un sistema que, fiel a la normativa, tiene los resortes para separarla de su actividad profesional, mientras que son otras las voces que le proponen seguir como colaboradora en la escuela. Una maestra que reivindica que se le escuche, que se le personifique y, en definitiva, que estudien su caso.
\end{abstract}

\section{Palabras clave}

Educación Infantil, Narrativa, Profesión Docente, Sistema Educativo

\begin{abstract}
They say that the teacher is born and done. In the greatest case, that is possible. However, and in this case, she is exposed to countless circumstances that may interfere in your professional and even personal development. But the narrative, as a methodological proposal, places us in the place of a child teacher who for health reasons is invited out of the educational system: retired. Therefore, the objective of the research is: "Know and understand the vital trajectory of a child teacher once she is retired due to illness". So that, the interview put in the position of a professional who suffers but she does not succumb. The disease has not been enough but will have to face a new situation, likewise, not wanting. A woman who knows she's qualified and could still be tied to her work. A system that adheres to the norm has the springs to take it out and others are the voices that propose to continue as collaborator. A
\end{abstract}


teacher who claims to be heard and to personify and study each case.

\section{Key Words}

Child Education, Narrative, Educational System, Teaching Profession

\section{INTRODUCCIÓN}

\subsection{Un contexto en tres partes}

No es que se puedan dar las dos cosas a la vez. Pero, una maestra en activo es aquella que desempeña a diario su trabajo. Entra en el aula, establece su asamblea, propone las actividades, o bien proyecta sus actividades, presenta al invitado del día y, a veces, sale de visita o lee con los abuelos un cuento. Mientras que jubilada significa que está apartada de este quehacer. Es decir, la administración cesa de sus obligaciones laborales a la trabajadora y su situación pasa a ser la de pasiva. Pero este supuesto se puede dar por tres razones aparentes: a) por edad máxima de actividad laboral, b) por incapacidad para desenvolver su trabajo, y c) por una enfermedad. En nuestro caso, la maestra en plenitud de facultades se ha visto impedida por una situación de salud grave, con un resultado de dolencia crónica. Tras un proceso de lucha contra la enfermedad el sistema, amparándose en los informes médicos y en la legislación vigente, opta por su cese laboral irreversible.

Esta enfermedad dolorosa y adversa, se presenta en la paciente de varias formas. En principio, de todas esas maneras con que se manifestó en su cuerpo y mente se le ha podido vencer, pero no se contaba con un último modo de presentación y darse a conocer. Nos referimos a la del ámbito laboral, el cual ha doblegado las intenciones de volver al trabajo como profesional de la educación infantil (Lledó, 2018; Fendler, 2003). O sea, la enfermedad fue plegada tras un largo proceso de lucha médica, física y psicológica, pero ¿y ahora qué? Tras sentirse mejor, creer haber comenzado a terminar con la pesadilla, una nueva realidad, a modo de controversia, se ciñe sobre ella: la jubilación anticipada (Amar, 2018).

Una vez se diagnostica la enfermedad, el protocolo se activa y, en breve, se pone en práctica un tratamiento agresivo que hace que, al poco tiempo, su aspecto físico cambie y la persona se vea muy diferente. Los corticoides y demás fármacos hacen su trabajo, pero también dejan sus secuelas. Los goteros se perpetúan en los meses y el cansancio ya no se puede disimular, además de manifestarse con un singular cambio de imagen. El resultado se lo pueden imaginar. Un pañuelo en la cabeza ocupa el lugar de aquellos cabellos.

Tras el cambio físico, existe otro de ámbito social. Es evidente que su aspecto ya no es el mismo y las personas que la aprecian dudan, o no, en preguntar. La preocupación por esta persona estimada hace que no puedan aguantar más y preguntan por su estado de ánimo y de salud en general. La maestra se termina acostumbrando pues se interesan por ella desde los familiares a los vecinos, pero, igualmente, compañeros de trabajo y madres y padres de sus alumnos. Con comentarios que van desde "no sabía nada", hasta "me he quedado de piedra al verte", pasando por "lo joven que eres", o bien, "con la salud que tenías" ... Con todo, no sabemos si mejoran o empeoran la situación. 
Pero la maestra se hace fuerte y pone buena cara (Rice, 2006). La sonrisa del aula (Amar, Peláez y Oliva, 2020), la que mantenía para su alumnado y familiares o compañeros de trabajo, se torna ahora en mueca de educada réplica. La enfermedad fue superada en la parte privada. En el hogar, junto a los suyos, se ha empezado a pasar página. Ciertamente, no se ha cerrado por completo la historia, pero ese capítulo no se vuelve a tocar/comentar más. Ahora bien, con el apartado público también se ha de saber lidiar. Es de menor trascendencia pero puede ser, en determinados momentos, duro de esgrimir. La parte social está más expuesta, mientras que la primera es más íntima. Ambas son las dos caras de esta moneda llamada enfermedad. En ella se han experimentado sensaciones físicas y otras tantas emotivas que han determinado su actual personalidad y carácter.

Pero aún queda un tercer episodio en el transcurrir de la enfermedad. Una vez se ha creído, en la acepción de que ya no queda duda, que la enfermedad es historia pues, de nuevo, el cabello rizado y espeso se peina todas las mañanas y se empieza a sentir mejor en general, se propicia un nuevo estado anímico y se reactiva su energía vital. Todo se alía con las pruebas médicas que, en su mayoría, confirman que el ayer ya es mejor empezar a olvidarlo. Ahora ha de aprender a mirar hacia el futuro. Ha de disfrutar junto a los suyos y volver a sonreír a la vida.

\subsection{El relato de su experiencia de vida}

“Érase una vez...". No se trata de un cuento de hadas sino de un relato, con su personaje, su trama y su posible final. Mientras que nuestra historia continúa así. Un buen día una notificación de la administración no la dejan en el buzón de su casa como se hace, habitualmente, con la mayoría de las cartas. Este documento oficial es entregado en mano con acuse de recibo y certificado. Una vez se abre y lee el contenido de la misma, ahora la enfermedad se muestra de otra manera; presenta una nueva cara. Al parecer, todavía, tenía otra faceta oculta. Creía que había vencido a la enfermedad y que su aspecto físico y anímico eran los mejores resortes para aparcar el doloroso pasado. Y la carta con sello oficial le viene a recordar que aún no está bien; o por lo menos para continuar trabajando.

En una persona sana podría ser interpretado como el final de un proceso laboral. Pero, en este caso, la juventud, la formación y el deseo de compartir con su alumnado los proyectos que fueron aparcados desde aquel día en que todo comenzó se ven, de nuevo, truncados y ahora, con visos de ser algo definitivo. ¿Qué hacer o decir? Acudir al sindicato, llamar a la administración o renunciar a todo. Su intención es la de restablecerse en la normalidad, en su deseo de maestra. Anclada en su formación y, sobre todo en su mejoría, promueve actuaciones de lo que ella considera justicia social (Zeichner, 2010).

Las opciones se suceden y todas topan con una realidad: el contenido de la carta. Que resumida queda en: "pasas a pasivos". Con la jubilación, nuestra maestra va a tener que aparcar muchos de sus proyectos profesionales, mientras que la energía renovada se diluye entre papeleos y visitas a la administración que enloquecerían a la mente más equilibrada. Le hacen recordar todo aquel ayer, y repetir lo mismo, como si no hubiese maneras de evitar este nuevo sufrimiento y, además, todo es concluyente con: hasta aquí hemos llegado. 
En este entramado se establece un dilema: ¿Qué papel juega la maestra? Pero, da la sensación que todo se torna o termina convirtiéndose en una estrategia tecnócrata; donde se obvia la parte profesional y vocacional que la asegura como una docente cualificada. En este sentido, estamos hablando de una persona competente para desempeñar su labor docente, con conocimientos y práctica, lo que la erige en una profesional con experiencia y destrezas que la capacitan para la función docente actuando, eficazmente, con su alumnado, con los compañeros, la familia y la institución. Pese a los informes médicos que pronostican mejoría, todo apunta hacia un final no deseado.

El hecho de admitir lo que son ciertos "ecos de transformaciones más profundas" (Brey, 2009, p. 12) a la maestra de infantil no le solucionan su situación. Con su lucidez tendrá que establecer una trama o, al menos, intentarlo. No ha de renunciar a su sueño; del que otros se han hecho dueños.

\subsection{La lucha contra la realidad}

La labor que desempeña una docente cualificada es algo más que un "compromiso laboral" (Zabalza, 2007, p. 91). Se entremezcla con un profundo conocimiento del oficio del educador junto a una vocación (Córdova, 2007), que se va profesionalizando en beneficio de unos resultados a favor de la comunidad socio-educativa, implicándose y siendo responsable, diseñando e innovando, siendo creativa y crítica (Carbonell, 2015). Y esta singladura se trunca por causa de un revés de la vida y el desarrollo laboral, definitivamente, se aparca.

Pero ¿cómo se lo comunican a la persona implicada?, ¿cómo se lo tomaría ella? y ¿qué consecuencias podría tener? La maestra en sí es funcionaria de carrera; tras años de formación, incluso obteniendo un doctorado y con docencia, también, en la Universidad y perteneciendo a un grupo de investigación, ¿cómo se sentiría? Se le presenta una carta y otro escrito más y, al poco tiempo, le llega otra firmada por el responsable político que le agradece el tiempo de servicio. Las autoridades suscriben lo que el mensaje dicta y el proceso empieza a insinuar el fin de una etapa para comenzar otra: la jubilación no deseada pues la maestra se siente útil y con ganas de seguir trabajando. Resulta fácil enunciarlo y complicado admitirlo. El factor psicológico de nuevo se agudiza. Ella creía haberse recuperado de este hándicap; se había repuesto con más o menos ayuda. Pero de nuevo le recuerdan algo que no quería volver a escuchar: las múltiples consecuencias de una enfermedad indeseable que podrían ser transitorias o de por vida.

Tal vez, todo quede resuelto con una buena compensación económica. De forma elegante, le vienen a recordar que ha de vivir lo que le quede y puede hacerlo, al menos, con dignidad salarial. Pero, no nos olvidemos que ella quiere seguir trabajando. Había dejado aparcados en la gaveta de su aula proyectos y trabajos para su alumnado y con los padres. La docente, en este caso, se convierte en un "sujeto" que sufre en su colchón económico. No obstante, padece y está a merced de los envites y necesidades de la legislación tanto por parte de la "macropolítica como por la de la micropolítica" (Imen, 2008, p. 239). Sin embargo, ¿cuántas preguntas se continúa haciendo la docente sin encontrar respuestas? Posiblemente, algunas de esta índole: 
“¿Existe una relación real entre trabajo y salud? ¿Influyen las condiciones de trabajo en las que realizamos los docentes nuestra actividad en la salud? ¿Por qué a veces me siento deprimido? ¿Tengo derecho a un chequeo médico? Muchos docentes se han formulado esas preguntas alguna vez y sin embargo muy pocas veces han encontrado respuesta a las mismas" (Pérez Soriano, 2009, p. 13).

$\mathrm{O}$, quizás, las respuestas que ella recibe son taxativas y se remiten a un recetario de normas y leyes vigentes. Pese a todo, la maestra de infantil se siente en la necesidad de recurrir a un equipo de abogados. Ella quiere ampararse en su deseo: "Yo quiero seguir trabajando y creo que lo puedo hacer". Ahora bien, la administración considera lo contrario. Y, probablemente, e insistimos en ello, la enfermedad está siendo superada. Pero, en este momento, no estaría de más tener una ayuda psicológica. $\mathrm{Y}$ la pregunta es la siguiente: ¿se la ofrece la administración? O simplemente ¿eres trabajadora de la administración educativa, en calidad de docente, tan solo cuando estás en activo? Seguramente, la respuesta esté en que puede pasar a ser examinada por salud mental. Y esto pertenece a otra administración. La gente que la quiere le dice que la práctica del pilates o el yoga le harán mucho bien. Ella interpreta que son consejos piadosos y bien intencionados.

Con todo, la docente siente que ha superado la dolencia, ya que los documentos médicos así lo están certificando. Y cuando empieza a encontrarse mejor, incluso con voluntad de volver a trabajar, le llega la carta y todo le ha de quedar muy claro. Mientras asimila la nueva situación laboral, que para algunos podría ser un caso de liberación y recompensa, para nuestra docente le supone un nuevo delirio y una nueva experiencia no deseada. Es más, ¿quién le ha consultado o dado la opción de la jubilación obligatoria?

Y dentro del añorado desarrollo profesional (Imbernón, 2017), en plenitud de capacidades, al menos, eso cree -de nuevo, en la acepción de no dudar-y después de haberlo demostrado y mostrado en varias ocasiones y foros profesionales, la vida laboral llega a su fin.

Ahora bien, ¿cómo se aprende a enseñar? En este caso, tuvo varios años de formación inicial y permanente (González y Barba, 2014). Y, de repente y sin previo aviso, debe aprender a estar jubilada. Encontrándose mejor y dispuesta, tiene voluntad de volver al aula y no desea que la jubilen. Lo que Day (1999, p. 4) llamaba "aprendizajes naturales", éste de verse jubilada debe ser un aprendizaje más de la vida, pero desnaturalizado. Para nuestra maestra de infantil es lo más adulterado que le ha podido pasar en su carrera profesional. Y se mezcla el bucle entre lo personal y lo profesional. Con lo primero, le recuerda que no ha superado la enfermedad y, con respecto a lo segundo, esta nueva situación hace que todo redunde en lo primero. $\mathrm{Y}$ en vez de hacer crecer a la persona, ella se sume en un nuevo estadio de incomprensión. Su vida profesional entra en una nueva etapa; pero ahora nadie le enseñó nada y le llega de sopetón.

Ya no existen oportunidades, creatividad o práctica innovadora (Perrenoud, 2007). A lo que se le invita es a volver al dulce hogar o, en el mejor de los casos -pues "con lo joven que eres y lo que vales"- puede volver al centro pero como colaboradora, por ejemplo, con un voluntariado. $\mathrm{Y}$ es la maestra de infantil quien comenta que: "Hay personas que te dicen que te puedes hacer cargo de la biblioteca del colegio, implicarte más en la Asociación de Padres y Madres, hacer cualquier tipo de voluntariado en la escuela o en la esfera social". Y le repiten que podría aprovechar todo lo que ha 
trabajado en el centro para poner en marcha una asociación o, mejor dicho, una escuela de Padres.

Y del desarrollo profesional se pasa a admitir un nuevo estadio de desenvolvimiento personal donde se sustituyen las obligaciones y responsabilidades en el aula por otras de tipo más altruista y filantrópico, que realizará como acciones puntuales. Pero una vez más nos cuestionamos: ¿es lo que quiere o necesita nuestra maestra de infantil?

En el oficio de enseñar (Vaillant y Marcelo, 2015) se le aleja de los cargos o espacios de responsabilidad. Se admitiría que la docente estaba habilitada para dar clases. Se había formado durante años y lo había demostrado en su práctica profesional. Continuó su formación, publicó e investigó, y ¿ahora qué? Sobre este particular, la normativa tiene claro lo que ha de decir; pero ¿es "normal”? Y, en este sentido, es evidente que:

“Junto con el poder epistemológico dado por el fortalecimiento de su conocimiento, ser profesional significa poder decidir e influir en el cambio educacional, es decir, contar con poder político... El desarrollo profesional involucra entonces la oportunidad para fortalecer las condiciones que permiten el ejercicio de poder profesional: lo que se denomina en inglés 'empowerment'”' (Ávalos, 2000, p. 4, citado en Marcelo y Vaillant, 2009, p. 79).

Queda patente que nuestra docente ya tuvo su reconocido mérito en la función docente. Pero, ¿por qué no permitirle sentirse válida en otro ámbito de la administración o la gestión educativa? No tenemos nada contra el voluntario. Que estamos seguro que lo haría, pues le interesa y es una acción procomunitaria necesaria. No cuestionamos este espacio de servicio público y prosocial. Lo que quisiéramos debatir, que quede constancia, es sobre la imposibilidad de haberle dado a elegir.

En este sentido y una vez centrado el estado de la cuestión que estamos valorando, lo que debería ser el mejor espectáculo del mundo, o sino acérquense a un aula de infantil y vean cómo trabajan los profesionales cualificados... se podría convertir en un evento escénico de poca categoría, aburrido y previsible. Lo que tenemos claro es su deseo de retornar al aula y ello volvería a ser la mayor experiencia del mundo; por lo menos para esta profesional formada y con vocación de maestra de educación infantil.

\section{METODOLOGÍA}

A partir de este objetivo: "Conocer y comprender la trayectoria vital de una maestra de infantil una vez es jubilada por enfermedad", hemos optado por la metodología cualitativa de corte narrativa, ya que centrará mejor la intención de compartir la palabra con una persona epistemológicamente válida. Ahora bien, sin registrar su voz, el sentir o sus pensamientos, tal vez, todo quedaría soslayado y condenado al olvido, diluyéndose con el paso del tiempo. En la mayoría de investigaciones, estos pareceres adquieren relevancia en pocas ocasiones. La dinámica es investigar sobre los grandes hechos o teorías educativas, así como sobre las experiencias relevantes o proyectos de innovación en educación.

Pero ¿quién compartiría la palabra con una maestra de infantil que quiere volver al aula después del relato que se está presentando? Y, del mismo modo, ¿quién estaría más autorizada para hablar de su propia experiencia que la persona que la vivió en primera persona? O ¿por qué no conocer una narrativa que ha marcado una vida? El conocerla, posiblemente, nos haga mejores personas y mejores profesionales (Clandinin y Connelly, 2000; Denzin y Lincoln, 2012). Somos de la opinión que, conocer las voces 
de la educación, nos hará "comprender mejor" y, por consiguiente, establecer las “condiciones para transformar el mundo" (Rivas, 2009, p. 29), haciéndolo más justo y legítimo.

Igualmente, la investigación bio-narrativa se establece sobre dos baluartes (Landín y Sánchez, 2019, pp. 227-242). Primero, la generosidad de la narradora que comparte su historia, a veces levantando asperezas del ayer. Y, en segundo lugar, la propia subjetividad que se valora. Además, debe mantenerse un escrupuloso respeto a su privacidad, y ser fiel a lo narrado, sosteniendo el compromiso ético propio de la investigación cualitativa (Roth y Unger, 2018). Igualmente, su palabra es valorada pero, asimismo, no olvidamos la trascendencia de su voz. La informante contó con nuestro reconocimiento y participó en todo el desarrollo de la investigación. Desde el principio, se erigió en la protagonista con una entrevista semiestructurada que permitía su participación. Y, al final de la investigación, le presentamos un primer informe con el propósito de poder mejorarlo con sus comentarios. Pero lo más destacable sería la intención que mantenemos, en este tipo de investigación cualitativa, de querer “contribuir a transformar el mundo" (Moriña, 2017, p. 17).

Un modelo de investigación donde la neutralidad se erige como parámetro de referencia. Donde la subjetividad (Arfuch, 2002), es sinónimo de lo que le pertenece, como sujeto activo, pero dentro del conjunto social, de sentimientos y obras (León y Zemelman, 1997). Y para abundar más en este sentido, añadiríamos que:

"Hacer uso de la narrativa es interesarse, principalmente, por las "voces" propias de los sujetos y del modo cómo expresan sus propias vivencias. A través de este enfoque se pueden reproducir las experiencias de la vida, tanto personal como social, de forma relevante y llena de sentido. Se trata de proporcionar una imagen "fiel a la vida" de lo que la gente dice y del modo en que actúa; se deja que las palabras y las acciones de las personas hablen de sí mismas” (de Mattos Medina, 2011, p. 97).

Con todo, ya hemos adelantado algo de las características de nuestra informante. Una mujer de mediana edad, profesional de la educación infantil y funcionaria de carrera, hasta el día que todo se truncó por causa de un cáncer de mama. Doctora en Educación, siempre militó en los derechos de los más desprotegidos y se reconoce una feminista del siglo XXI. Se alejó de la docencia universitaria pues no le interesaba el sistema de "pleitesías" y hasta de "obediencia" que impera con determinadas personas. Prefirió presentarse a unas oposiciones de educación infantil, con méritos, antes de proseguir en la Universidad por meritaje. Autora de libros, de artículos en revistas nacionales e internacionales, e invitada a congresos se presenta como una persona que ama la educación, en el amplio sentido del término. No concibe la educación infantil sin la colaboración de la familia y abre las puertas de su aula para que todos participen del espectáculo/experiencia que supone ver aprender a sus hijos o nietos. Le gusta trabajar por proyectos y sacar a su alumnado a visitar el barrio o contribuir en un mercadillo de intercambios de libros solidarios. Confecciona con los familiares un grupo interactivo de lectura y, en la actualidad, aquella iniciativa que impulsó en solitario, ahora es suscrita por otras compañeras de ciclo.

En cuanto a la participación en esta investigación nunca se opuso. Y siempre se mostró con voluntad de participar en las entrevistas. No puso en duda el valor de la metodología cualitativa, decía "vengo convencida, no tienes que insistirme". Conocía el procedimiento y siempre se mostró afín. Nuestras entrevistas, hasta cuatro de una hora 
cada una, se dilataban en el tiempo pues inevitablemente los recuerdos se sucedían cuando se narraban experiencias de vida que eran dolorosas para ella. No obstante, las entrevistas, en ocasiones, adquirieron un matiz emotivo y los recuerdos personales hicieron que tuviésemos que pararlas. Por lo que algunas de las respuestas rozaron lo íntimo y provocaron en el entrevistador una extraña sensación de invasión e intrusismo en lo privado. Sin embargo, la elegancia y la comprensión de la entrevistada paliaban esta sensación. Las entrevistas fueron estructuradas en cuatro bloques, uno por día de conversación (Rapley, 2014): su aula, su vocación-profesión, su jubilación y, por último, su futuro. Cabría aclarar que el establecimiento de los cuatro bloques fue elaborado previamente a las entrevistas por el investigador; que se abordó en términos generales como un antes, un durante y un después de su experiencia profesional y personal.

La metodología narrativa propicia este interesantísimo encuentro y el conocimiento de una experiencia valiosa de desafío personal. Bolívar y otros (1998) aportan una importante guía para iniciar y acompañar esta investigación de corte biográficonarrativa en el ámbito de la educación, que se ancla sobre núcleos de interés para la informante (la profesión, la familia o la jubilación, entre otros).

Por último, en esta investigación los resultados se mezclan con la discusión. Y, al final, se redactan una serie de conclusiones que tienen centrado su interés en la importancia de escuchar a la maestra de infantil y su deseo de sentirse útil con su profesión. Hace falta saber reinventarse aunque, en ocasiones, puede costar demasiado esfuerzo y apenas quedan estructuras, tras una dolorosa enfermedad, para continuar luchando; ahora, contra la administración.

\section{RESULTADOS}

La entrevista (Kvale, 2011) se inició con una simple pregunta, que se abre en partes con aristas, generando debate: ¿por qué te gusta tu trabajo? La respuesta no se hace esperar: "me gustaba, me acaban de apartar de él". Ante ésta afirmación se empezó a comprender, en cierto modo, por dónde no se debía proseguir y hacia dónde nos adentrábamos. Por tanto, tuvimos que reformular la pregunta con: ¿qué es lo que destacarías de tu trabajo? Y se obtuvo la siguiente contestación: "con mi trabajo me sentía realizada, me gustaba lo que hacía y era un proyecto siempre ilusionante y cambiante con los niños. Yo diría que era muy divertido". Ahora bien, la clave de este entusiasmo por trabajar en infantil lo fundamenta en que:

"Yo nunca lo tuve como una obligación, era algo más que mi modo de ganarme un sueldo. Lo tenía como la manera de realizarme. Me agradaba muchísimo ir a trabajar, pues no lo sentía o me suponía una molestia o una pesadez".

Pero de nuevo, el verbo en pasado cobra presencia, ya que se expresa con "a mí me gustaba lo que hacía", además de introducir una nueva acción "me divertía". E, igualmente, formula su respuesta alrededor de un pretérito inspirado en "aprendía mucho de mis alumnos, mis compañeras, de los cursos a los que asistía y de las familias".

Una profesión que cada día era nueva. Ya que, según ella, era "cambiante, aquí no había un dos más dos igual a cuatro, pues aunque proyectaras una actividad podría salir algo diferente y, todo ello, me motivaba". La maestra hace hincapié en que su 
profesión era "siempre enriquecedora y con los niños tan pequeños es algo muy vivencial". Se está ante una educadora de infantil ilusionada con su trabajo y, sobre todo, con su alumnado. Una maestra que valora la "cercanía con mis niños y niñas, además que se ve el avance por día". Al final suscribe, en esta parte de la entrevista, que la educación infantil es "muy bonita y gratificante".

Pero el éxito de su propuesta en el aula se centraba en la relación con su alumnado, por el que sentía una profunda admiración. Lo de trabajar lo interpretaba como una manera de percibir unos honorarios. Pero, asimismo, su mayor satisfacción radica en intentar llevarse bien con sus compañeras de trabajo, según ella, "una profesión muy feminizada" y, sobre todo, "el saber trabajar con la familia". La maestra comenta lo importante de las buenas relaciones con los padres y madres, pero también "con los abuelos o primos". Ella se refiere al amplio concepto de familia que es el primer y gran agente en el aprendizaje y socialización de los pequeños. E, igualmente, coloca un nuevo verbo en este debate: el de "participar" con la familia. En este sentido, lo narra a partir de sus experiencias con los grupos interactivos, en los cuales era imprescindible la familia. Y, seguidamente, habla de "abrir la clase" como puntal de éxito en la educación infantil. Y todo con un resultado: "los familiares me han superado siempre de manera positiva. Han aportado muchísimo a la clase".

Sin embargo, su experiencia la lleva a admitir que "habría casos puntuales en que las cosas no se hayan aclarado o que exista una persona más impertinente, pero todo se solucionaba dejando muy claro lo que se iría a realizar". Pero, hace hincapié en ello, el inicio del éxito está en "contar con ellos en todo el proceso".

En su trayectoria profesional reconoce no haber tenido confrontaciones serias con las familias y siempre el diálogo y la colaboración estarían sobre la mesa de trabajo. Es más, cuando surgía algún conflicto lo intentaba solucionar implicando aún más a esa familia y los resultados fueron "muy satisfactorios". A veces, "la clave estaba en no tener que pedirles las cosas sino dejar que las iniciativas salieran de ellos"; pues siempre se ha de "consultar y dejarles que tomasen decisiones. No presentarles las actividades cerradas, como meros cooperadores, sino incentivarles desde el principio, contando con ellos". E insiste una vez más: "la clase siempre estaba abierta a sus proyectos". Y, de este modo, vuelve a introducir un nuevo verbo en la narrativa; en el momento que dice que los padres, también, puedan "presentar" sus proyectos.

Estas buenas intenciones y predisposición por su clase, y por la dinámica que en ella debería imperar, obedecían a una profesional con vocación de maestra de infantil. Según la entrevistada, desde pequeña siempre quiso ser maestra: "recuerdo desde muy chica jugar al colegio con mis hermanos y vecinos, o con mis muñecas y yo, en la mayoría de las ocasiones, era la maestra". Luego, cuando fue creciendo, aquella vocación no desaparecía, incluso optó por "impartir clases particulares en mi casa o ir a domicilio". Estamos ante una persona que reconoce, abiertamente, que "siempre quise ser maestra". Y, en este momento de su narrativa, evoca cómo le gustaba corregir los trabajos de sus hermanos menores y prepararles las actividades, pues "era algo que me llamaba la atención y, además de este modo, les podía ayudar". Pero lo lúdico pasaba a otro plano más humano-profesional en el momento en que "yo admiraba y respetaba muchísimo a mis maestras".

Es curioso cómo su vocación empezó teniendo una vertiente entre hermanos, en su hogar y como un juego. Luego todo cambia, con el paso del tiempo, hacia una admiración a los docentes y a la escuela. El entusiasmo crece y desea hacerse una 
profesional de la educación infantil. Ella siempre quiso ser maestra de los "más pequeños, de los niños". Pero faltaba algo para confirmar la necesidad de ser maestra: el acceso a la Facultad de Educación. Y todo se ratificó cuando comenzó a realizar sus prácticas (en el extinto plan de estudios de Magisterio, las prácticas se iniciaban desde el primer curso). Luego y desde el momento en que empieza a entrar en el aula, ya como maestra funcionaria, se produce la verdadera confirmación de una vocación de antaño que, poco a poco y gracias a la formación inicial, se va erigiendo en profesión.

Y con el paso del tiempo la vocación, definitivamente, se hace profesión y la cualificación se mantiene en su ideario de maestra de infantil. La innovación fue un recurso en su quehacer dentro del aula (Carbonell, 2000; Gather, 2004). Sin querer enfrentarse directamente con el centro o a las otras compañeras reconoce que, en ocasiones, afloraron situaciones de desacuerdo que se hacían "inevitables, pues el método y las fichas no me seducían demasiado". De modo que, a ella le interesaba "trabajar por proyectos" y "siempre que fuera posible o hubiese consenso, ahí estarían los padres". Aunque en este momento rectifica matizando que "mejor hacer referencia a las madres que eran las que más venían a este tipo de actividades". Dando a entender que la profesión de maestro de infantil no solo está feminizada en cuanto a las docentes sino, también, en relación con las personas adultas que se vinculan al aula.

Una vez la entrevista adopta un matiz más personal con respecto al asunto de la jubilación por enfermedad, ella se refiere a ésta como "algo muy desagradable". Diferencia la jubilación tras un proceso laboral y la que se produce por obligación. Es más, determina que la suya es injusta pues "alguien considera que estás incapacitada para realizar tu trabajo". Pero su rabia se centra en que "esto me haya sucedido a una edad tan temprana como la mía" y, sobre todo, "porque me encontraba en plenitud de posibilidades para aportar a la clase, al centro y, en general, a la comunidad educativa". Y su argumentación sobre este parecer se centra en dos focos, ya vencidos: a) "sentirme más relajada, después de haber superado los miedos de los primeros años de profesión" y b) "el temor que te producen los cambios de centros, pues ahora era definitiva en mi colegio". Pero toda su controversia radica en que nadie le dio "la opción de ni tan siquiera a patalear, ya que la normativa es la que es". Y, por ello, la maestra a partir de este momento está incapacitada para "toda profesión u oficio, como así viene en la resolución". Y suscribe: "para mí ha sido un varapalo".

La maestra es testigo de cómo se inicia un proceso por parte de la administración educativa, por el cual se le informa de su nuevo régimen. Tras una llamada telefónica, y alguna que otra carta, todo se precipita en cuestión de meses. La inspección médica toma la iniciativa y la valoración no se hace esperar. Y, al poco tiempo, la resolución se hace pública. Toda la esperanza de volver, tras el fiasco de la enfermedad, se diluye en poco tiempo. Todas sus intenciones de poner fin a esta larga dolencia se ven truncadas. Y narra: "interpretaba que volver a mi colegio era volver al punto de origen". En este sentido, la maestra de infantil lo explica más y mejor: "estando muy feliz en mi trabajo, de repente salgo y no puedo volver". Su dolor se agudiza añadiendo que "yo siempre soñé en reincorporarme" y añade: "lo veía necesario".

Ante esa imposibilidad de volver a su centro, la entrevista se centra en si ella contempla algunas opciones de realizar determinado voluntariado, de modo que no se quede desvinculada de la educación infantil. Pero la maestra lo tiene muy claro: "Si la administración considera que yo no estoy apta para trabajar con mis alumnos, no entiendo por qué lo estaría para el voluntariado". En cierta manera, el voluntariado no 
lo descarta en su futuro, "pero en este momento de duelo no lo contemplo". Y añade al respecto: "Yo salí del colegio siendo maestra, con ese perfil para todo el mundo, y no me veo volviendo como madre colaboradora o bien como voluntaria". Reconociendo que podría aportar algo al centro, sin embargo, ella no está cómoda, "pues este nuevo perfil yo no lo he elegido".

Es más, su propuesta a la administración se centró en poder impartir clases en otro nivel, por ejemplo primaria en el que está habilitada. También, presentó la opción de participar en el equipo directivo, hacer trabajo de despacho, o bien involucrarse con los programas de biblioteca. Sin embargo, no le fue posible. La entrevistada cree "merecer más opciones para seguir trabajando", máxime cuando "ahora es en el momento en que me siento con más capacidad y seguridad para aportar algo". Es más, ella habla de “disfrute en los últimos cursos ..." ya que todo lo sustenta en su trabajo basándolo en la experiencia y en la tranquilidad que le han dado los años en la escuela. Asimismo, en todo su desarrollo profesional lo que persiguió fue "mejorar" y aún cree que podría haber aportado algo a la comunidad educativa, incluso, con o desde su enfermedad.

\section{UN FINAL CON MUCHOS FINALES}

Hemos participado de la narrativa (Tarrès, 2001; Bolívar, 2014; Goodson, 2004) de una maestra vocacional y profesional cualificada. Las relaciones con su alumnado, compañeras de trabajo y familiares es fundamental en su quehacer. Estamos ante una maestra capaz de aportar a la comunidad educativa (Arias-Cardona y Alvarado-Salgado, 2015). A todas luces, estamos ante un ejemplo de superación. No obstante, ahora y por las razones narradas, no está en su mejor momento y la administración educativa la ha jubilado.

Por lo apuntado, la vocación de maestra de infantil no se diluye con tanta facilidad. Perdura y persiste. Su deseo se ha anclado a esta aspiración. Y con este propósito de volver dejó todos sus materiales de aula guardados en su armario. No cerró la puerta a la intención de regresar a su aula o bien, en su defecto, pasar a primaria. Y todo porque quería verse "capacitada" para retornar a su puesto de trabajo, a su aula de infantil. Pero el deseo se diluye por imposición y el sueño de volver se torna en una pesadilla. Rechaza, en este momento, el voluntariado pues no le "apetece, me haría más daño que bienestar". Ni tan siquiera contempla volver, al menos por ahora, como colaboradora. El duelo lo ha de pasar y este dolor es el tiempo que una persona necesita para sanar las heridas de esta enfermedad tan desagradable, como es la que "padeció" nuestra maestra de infantil, también, en la vertiente laboral.

Volver al colegio significaba para ella el final de un largo proceso y el vencer, definitivamente, la enfermedad. El posible desarrollo del linfedema, los dolores articulares producidos por el tamoxifeno o las perturbaciones del dolor psicológico, probablemente, se hubiesen diluido antes con una posible reincorporación al aula de infantil.

Pero la reflexión final no ha de quedar en el apartado personal (Sancho, 2014) pues, también, tiene una vertiente administrativa y, ella, la cuestiona. Un ente administrativo, en palabras de la entrevistada, que está "despersonalizado" y ella propone "personalizar cada caso, estudiar uno a uno los expedientes y, sobre todo, darnos voz". La queja de la maestra se centra sobre la poca voz que ha tenido en el proceso. Todo se refiere a un 
reglamento, a una normativa, a una ley... La enfermedad es sobrevenida y la situación laboral es impuesta... Lo más normal es la situación en que se encuentra nuestra maestra de infantil. Está disconforme y decepcionada. Una vez ha pasado el duelo de la enfermedad, ahora tendrá que enfrentar otra pérdida: su puesto de trabajo.

La maestra es una persona y tal como ella señala "somos maestros y maestras que tratamos con personas y a nosotras, también, nos deben tratar como personas". Y sin abandonar el marco de las consideraciones finales, la voz sabia de la maestra de infantil reivindica el respeto, pues "no somos números, no somos un número de registro y ahí dos más dos, sí son cuatro". De esta forma, expone un sentir y cierra el círculo del deseo legítimo de ser considerada como persona, pese a las buenas intenciones del protocolo de la administración... Que tal vez haya pensado en ella, en su futuro, en su situación. Pero, en este sentido, la llamada que ella realiza se centra sobre la necesidad de que se estudie cada caso como algo único y personal. ¿Por qué no darle una segunda oportunidad? Y, adaptándose a las circunstancias complejas de nuestra informante, cabría atenderla en un conjunto de situaciones personales, físicas, emotivas o psicológicas... Sin olvidar que son sujetos y que forman parte del sistema. Son personas que trabajan en, con y para la educación.

La maestra de infantil en un momento dado de su narración apunta a que la administración "podría mejorar con respecto a los docentes que no quieran jubilarse, escuchándonos". Quizás, el protocolo que existe no es el mejor. Pero, la administración, ¿se ha cuestionado mejorarlo? ¿Está pensando en las personas, las mismas que trabajan para la administración educativa? Por ello, insistimos en: ¿es sensible a posibles mejoras? O bien, ¿sabrán que éste no es el único caso?

Esta enfermedad tiene como sufridoras a las mujeres y, verdaderamente, les afecta; derribándolas. Cabría decir que a todos los niveles. La víctima, en ocasiones, no se reconoce. Le pueden amputar un "trozo" de su cuerpo, que es visible y que se identifica con una parte importante de su feminidad. Y ¿la prótesis es la solución o ésta pasaría por la reconstrucción? Cada caso se interpreta y vive de una manera. Y, de igual forma, el duelo lo padecen de un modo particular. La administración educativa, también, ha de hacer su trabajo no solo el protocolario sino escuchando, siendo paciente con las pacientes. De esa manera, daría una lección magistral.

Abogamos por una administración educativa que personifique y estudie cada situación. Seguro que lo hace pero, en este caso, ha de satisfacer a la maestra de infantil. Sin embargo, da la impresión que la informante lo ha narrado de un modo muy diferente... Donde el convencimiento ha brillado por su ausencia y se ha impuesto la "incuestionable" normativa.

Lejos de realizar un final conclusivo, donde lo esperado hubiese sido un $a b c$ a modo de relatoría, en esta ocasión, hemos optado por la necesidad de escuchar a la maestra de infantil (Russell, 2018). Y hemos seguido a Barthes (1977, p. 11) quien sostiene que:

“Comprender un relato no es sólo seguir el desentrañarse de la historia, es también reconocer «estadios», proyectar los encadenamientos horizontales del «hilo» narrativo sobre un eje implícitamente vertical; leer (escuchar) un relato, no es sólo pasar de una palabra a otra, es también pasar de un nivel a otro".

En definitiva, hemos escuchado con atención lo que han sido sus demandas. Pues, al fin y al cabo, la versión transitiva del verbo escuchar se puede interpretar como atender a un consejo o aviso. Y, en este caso, viene de una persona: una maestra de educación 
infantil (Hayes, 2014). Y lo esencial en educación siempre son, y continuarán siendo, las personas...

\section{BIBLIOGRAFÍA}

Amar, V. (2018). Miradas y voces de maestros jubilados. Barcelona: Octaedro.

Amar, V., Peláez, J. y Oliva, E. (2020). Desde la más tierna infancia. En V. Amar (Coord.), Retos para la formación inicial. Desde las miradas y las voces de docentes en activo (pp. 145160). Barcelona: Octaedro.

Arfuch, L. (2002), El espacio biográfico. Dilemas de la subjetividad contemporánea. Buenos Aires: Fondo de Cultura Económica.

Arias-Cardona, A.M. y Alvarado-Salgado, S.V. (2015). Investigación narrativa: apuesta metodológica para la construcción social de conocimientos científicos. Revista CES Psicología, 8(2), 171-181. Recuperado de: https://www.redalyc.org/pdf/4235/423542417010.pdf

Barthes, R. (1977). Introducción al análisis estructural de los relatos. En S. Niccolini (comp.), El análisis estructural (pp. 65-101). Buenos Aires: Centro Editor de América Latina.

Bolívar, A. (2014). Las historias de vida del profesorado. Voces y contextos. Revista Mexicana de Investigación Educativa, 62(19), 711-734. Recuperado de:

https://www.redalyc.org/pdf/140/14031461004.pdf

Bolívar, A. y otros (1998). La investigación biográfico-narrativa en educación. Guía para indagar en el campo. Granada: FORCE.

Brey, A. (2009). Introducción. En A. Brey, D. Innerarity y G. Mayos, La sociedad de la ignorancia y otros ensayos (pp. 11-14). Barcelona: Infonomia.

Carbonell, J. (2000). La aventura de innovar: el cambio en la escuela. Madrid: Morata.

Carbonell, J. (2015). Pedagogías del siglo XXI: Alternativas para la innovación educativa. Barcelona: Octaedro.

Clandinin, D. y Connelly, F. (2000). Narrative inquiry: experience and story in qualitative research. San Francisco: The Jossey-Bass Education Series.

Córdova, N. (2007). Una reflexión sobre el oficio del maestro: vocación y formación. Perspectivas docentes, 35, 41-47.

Day, C. (1999). Developing teachers. The challenges of lifelong learning. Londres: Falmer Press.

De Mattos Medina, B. (2011). La voz del alumnado. Una investigación narrativa acerca de lo que siente, dice y hace el alumnado de magisterio de educación física en su formación inicial. Tesis doctoral. Almería: Universidad de Almería.

Denzin, N. y Lincoln, I. (2012). Manual de investigación cualitativa. Barcelona: Gedisa.

Fendler, L. (2003). Teacher reflection in a hall of mirrors: Historical influences and political reverberations. Educational Researcher, 32, 16-25.

https://doi.org/10.3102/0013189X032003016

Gather, M. (2004). Innovar en el seno de la institución escolar. Barcelona: Graò.

Goodson, I. (ed.) (2004). Historias de vida del profesorado. Barcelona: Octaedro-Eub.

González, G. y Barba, J. (2014). Formación permanente y desarrollo de la identidad reflexiva del profesorado desde las perspectivas grupal e individual. Revista de currículum y formación del profesorado, 18(1), 397-412. Recuperado de:

https://www.ugr.es/ recfpro/rev181COL12.pdf

Hayes, H. (2014). Currículum XXI. Lo esencial de la educación para un mundo en cambio. Madrid: Narcea.

Imbernón. F. (2017). Ser docente en una sociedad compleja: La difícil tarea de enseñar. Barcelona: Graó.

Imen, P. (2008). Trabajo docente: Debates sobre autonomía laboral y democratización de la cultura. En D. Andrade Oliveira y M. Feldfeber (Comps.), Políticas educativas y trabajo 
docente: Nuevas regulaciones ¿nuevos sujetos? (pp. 239-258). Buenos Aires: Novedades Educativas.

Kvale, S. (2011). Las entrevistas en investigación cualitativa. Madrid: Morata.

Landín, Ma . y Sánchez, S. (2019). El método biográfico-narrativo. Una herramienta para la investigación educativa. Educación, XXVIII (54), 227-242.

https://doi.org/10.18800/educacion.201901.011

León, E. y Zemelman, H. (Coords.) (1997). Subjetividad: umbrales del pensamiento social. Barcelona: Anthropos.

Lledó, E. (2018). Sobre la educación. Madrid: Taurus.

Marcelo, C. y Vaillant D. (2009). Desarrollo profesional docente: ¿Cómo se aprende a enseñar? Madrid: Narcea.

Moriña, A. (2017). Investigar con Historias de Vida: Metodología biográfico-narrativa. Madrid: Narcea.

Pérez Soriano, J. (2009). Manual de prevención docente: riesgos laborales en el sector de la enseñanza. Valencia: Nau Llibres.

Perrenoud, P. (2007). Desarrollar la práctica reflexiva en el oficio de enseñar. Barcelona: Graó.

Rapley, T. (2014). Los análisis de la conversación, del discurso y de documentos en investigación cualitativa. Madrid: Ediciones Morata.

Rice, N. (2006). Teacher education as a site of resistance. En S. Danforth y S. Gabel (Eds.), Vital questions facing disability studies in education (pp. 17-31). Nueva York: Peter Lang.

Rivas, I. (2009). Narración, conocimiento y realidad. Un cambio de argumento en la investigación educativa. En I. Rivas y D. Herrera (Coords.), Voz y educación. La narrativa como enfoque de interpretación de la realidad (pp.17-36). Barcelona: Octaedro.

Roth, W-M. y Unger, H. (2018). Current Perspectives on Research Ethics in Qualitative Research. Forum: Qualitative Social Research, 19(3). http://dx.doi.org/10.17169/fqs-19.3.3155

Russell, T. (2018). A teacher educator's lessons learned from reflective practice. European Journal of Teacher Education, 41(1), 4-14. doi: 10.1080/02619768.2017.1395852

Sancho, J. (2014). Historias de vida: el relato biográfico entre el autoconocimiento y dar cuenta de la vida social. Praxis educativa, 18(2), 24-33. Recuperado de: https://cerac.unlpam.edu.ar/index.php/praxis/article/view/898/866

Tarrés, M. (2001.). Observar, escuchar y comprender sobre la tradición cualitativa en la investigación social. México: FLACSO y El Colegio de México, Porrúa.

Vaillant, D. y Marcelo, C. (2015). El ABC y D de la Formación Docente. Madrid: Narcea.

Zabalza, M. (2007). Competencias docentes del profesorado universitario: Calidad y desarrollo profesional. Madrid: Narcea.

Zeichner, K. (2010). La formación del profesorado y la lucha por la justicia social. Madrid: Morata. 